\title{
Progress in the understanding of the etiology and predictability of fetal growth restriction
}

\author{
Li Tang ${ }^{1,2}$, Guolin $\mathrm{He}^{2}$, Xinghui Liu² and Wenming $\mathrm{Xu}^{1,2}$ \\ ${ }^{1}$ Joint Laboratory of Reproductive Medicine, SCU-CUHK, Key Laboratory of Birth Defects and Related Diseases of \\ Women and Children, Ministry of Education and ${ }^{2}$ Department of Obstetric and Gynecologic Diseases, \\ West China Second University Hospital, Sichuan University, Chengdu, People's Republic of China
}

Correspondence should be addressed to W Xu or G He; Email: Xuwenming@scu.edu.cn or heguolin19@163.com

\begin{abstract}
Fetal growth restriction (FGR) is defined as the failure of fetus to reach its growth potential for various reasons, leading to multiple perinatal complications and adult diseases of fetal origins. Shallow extravillous trophoblast (EVT) invasion-induced placental insufficiency and placental dysfunction are considered the main reasons for idiopathic FGR. In this review, first we discuss the major characteristics of anti-angiogenic state and the pro-inflammatory bias in FGR. We then elaborate major abnormalities in placental insufficiency at molecular levels, including the interaction between decidual leukocytes and EVT, alteration of miRNA expression and imprinted gene expression pattern in FGR. Finally, we review current animal models used in FGR, an experimental intervention based on animal models and the progress of predictive biomarker studies in FGR.
\end{abstract}

Free Chinese abstract: A Chinese translation of this abstract is freely available at http://www.reproduction-online.org/content/153/6/ R227/suppl/DC1.

Reproduction (2017) 153 R227-R240

\section{Introduction}

Fetal growth restriction (FGR) is a common pregnancy complication, which occurs in $5-10 \%$ of all pregnancies. It is the primary cause of perinatal mortality and morbidity. FGR is diagnosed by combining biometric measurement of fetal size with certain functional parameters to distinguish it from small for gestational age (SGA). Biometric measurement of fetal size signifying abdominal circumference or estimated fetal weight below the $3 \mathrm{rd}$ or 10 th percentile indicates FGR. Functional parameters include either a solitary parameter, namely, absent end-diastolic flow (AEDF) in the umbilical artery or contributory parameters such as pulsatility index $(\mathrm{PI})$ of the umbilical or uterine artery $>$ p95, or cerebroplacental ratio $(\mathrm{CPR})<\mathrm{p} 5$ (Bamberg \& Kalache 2004, Nardozza et al. 2012, Seravalli \& Baschat 2015, Gordijn et al. 2016). Gestation is a critical period for developmental programming. Children surviving FGR are at a greater risk of developing neurodevelopmental dysfunction in childhood (Miller et al. 2016) and cardiovascular (Zohdi et al. 2015) and/or metabolic diseases in later life (Bale 2015). FGR also affects hormonal regulation and is associated with permanent changes in hormone levels. Additionally, individuals with FGR have a higher tendency to develop obesity (Ornoy 2011). Increased risk of cardiovascular disease results from increased workload of the fetal heart associated with postsystolic shortening and fetal exposure to higher levels of maternal cortisol (Jansson \& Powell 2007, Crispi et al. 2014). FGR is a heterogeneous disease with varied clinicopathological subgroups. FGR preterm infants are more prone to postnatal infection with a disproportionately small thymus and low leukocyte, lymphocyte and macrophage counts (Longo et al. 2014). Late-onset FGR, which occurs after 32 weeks of gestation, is more complicated with less characteristic histological changes and its underlying mechanism still remains unknown (Mifsud \& Sebire 2014). To date, timely and accurate prenatal detection of FGR is still a challenge. Preterm delivery is a major strategy to resolve this problem but may result in a nonviable fetus (Monier et al. 2015).

Emerging evidence indicates frequent association of placental insufficiency with the development of idiopathic FGR, signifying the absence of genetic or structural defects in the fetus. Placental insufficiency accounts for $70 \%$ of all FGR cases. It is caused by the failure of conversion of uteroplacental arteries, which is characterized by hypercoagulable state and placental thrombosis (Murthi et al. 2010, Higashijima et al. 2013). A new mouse model of FGR using selective ligation of one of the two uterine arteries mimicked multiple characteristics of placental vascular insufficiency in humans. Phenotype of this mouse model indicated 
decreased birth weight of fetus. In addition, significant reduction was seen in placental labyrinth depth, volume and expression of placental growth factor (PGF), insulinlike growth factors-1 (IGF-1), and IGF-2 in placenta (Habli et al. 2013).

Placental dysfunction refers to the inefficient functioning of the placenta, which still meets the homeostatic requirements, resulting in babies born alive but small. Compared with placental dysfunction, placental failure is a more severe phenotype. Placental function is a critical regulator of fetal growth and development, and a mediator of fetal programming (Jansson \& Powell 2007). During the early stage of pregnancy, the placenta is derived from the trophectoderm, the outer layer of blastocyst and functions as the fetal renal, respiratory, hepatic, gastrointestinal, endocrine and immune systems (Guttmacher et al. 2014, Lanner 2014). Comparative analysis of lgf2 placental-specific P0 (Igf2-P0) knockout (KO) mice and Igf2-total $\mathrm{KO}$ mice indicate the specific role of placental dysfunction in determining the phenotypes of FGR. Since Igf2-P0 transcript is predominantly expressed in the fetal labyrinthine trophoblast, the key exchange barrier for nutrients, Igf2-PO KO mice created by deletion of the $\mathrm{U} 2$ exon in the P0 promoter region show placental dysfunction and FGR because of an imbalance between fetal demand and placental supply. However, as the transcription of lgf 2 is unaffected in the fetus, Igf2-PO KO mice eventually reach an equivalent size to wild type (WT) adults. Alternatively, in lgf2-total $\mathrm{KO}$ mice the expression of four main lgf2 transcripts is inhibited in both the fetus and placenta. As a result, they develop FGR but remain small for life because of balanced but reduced fetal demand and placental supply (Mikaelsson et al. 2013).

Shallow extravillous trophoblast (EVT) invasion is associated with the development of FGR, resulting in abnormal placental formation and poor remodeling of the spiral artery. Defective remodeling of the spiral artery retains the contractile properties. This causes the hypoperfusion-reperfusion phenomenon that damages the villous architecture, eventually impairing the maternal-fetal exchange (Burton et al. 2009). Consequently, understanding the underlying mechanism of this pathological alteration is of great importance (Kadyrov et al. 2006). Invasion of EVT is a spatially- and temporally-dependent process controlled by a series of precise regulations (Zhu et al. 2014). This process is associated with interstitial trophoblast invasion, synthesis of nitric oxide and endothelial adhesion molecules in extravillous trophoblast, and the expression of selectins in maternal uterine endothelial cells. It is negatively regulated by macrophage-induced apoptosis of the trophoblast (Kaufmann et al. 2003). A fine balance between the production/activation of proteolytic proenzymes also characterizes it. Increased levels of matrix metalloproteinases (MMPs) with proteolytic functions, namely, collagenases, MMP-8, stromelysin-3 (MMP11) and gelatinases (MMP-2 and -9) are reported to be related to FGR. Reduced levels of tissue inhibitors of metalloproteinases-1 (TIMP-1) and -3 are found in the placenta of FGR. They inhibit the MMPs by binding to their active sites (Zhu et al. 2014). In the present review, the pathological alterations associated with FGR, including dysregulated angiogenesis, microRNAs, imprinted gene, immune response in the placenta, and the interaction between EVT and decidual leukocytes are discussed. In addition, animal models, experimental intervention and potential predictive biomarkers of FGR are reviewed.

\section{Pathological factors associated with FGR}

\section{Hypoxic stress and reduced placental angiogenesis in FGR}

Angiogenesis is a major mechanism involved in the process of placentation. It is a complex biological process wherein new blood vessels are formed from preexisting ones in response to hypoxia (Biyashev \& Qin 2011). Normal pregnancy is associated with a balanced angiogenic state, while pregnancies complicated by FGR are often characterized by an anti-angiogenic bias. Accordingly, enhanced levels of anti-angiogenic factors, such as soluble fms-like tyrosine kinase-1 (sFlt1), and decreased levels of proangiogenic factors, such as neuropilin-1 and placental growth factor (PGF) are seen in maternal circulation and the placenta (Girardi et al. 2006, Herraiz et al. 2015, Maulik et al. 2016).

The vascular endothelial growth factor (VEGF) family of growth factors and receptors comprise an important signaling pathway in angiogenesis. By binding to the respective receptors, these growth factors stimulate endothelial cell proliferation, migration and new vessel formation. Enhanced VEGF-A (commonly referred to as VEGF) gene activity in human placenta is associated with early-onset FGR. Rather than a key parameter in the etiology of FGR, increased placental VEGF-A gene activity is considered as a secondary response to hypoxic condition in the uterus (Szentpeteri et al. 2013). Hypoxic stress is common in placental insufficiency. Analyses of existing mice and rat models of antenatal maternal hypoxia-induced FGR, by Jang and coworkers concluded that $14 \%$ or lower level of oxygen for 3 days or more is sufficient to produce FGR in rodents. The duration of hypoxic exposure rather than the degree of hypoxia is significantly more effective in determining the development of FGR (Jang et al. 2015) (Fig. 1). During the first trimester of pregnancy, hypoxic intervillous space (IVS) resulting from plugs within maternal arteries formed by proliferative cytotrophoblast (CT) is pivotal for both placental and embryonic development. Abnormal maintenance of IVS hypoxia results in 


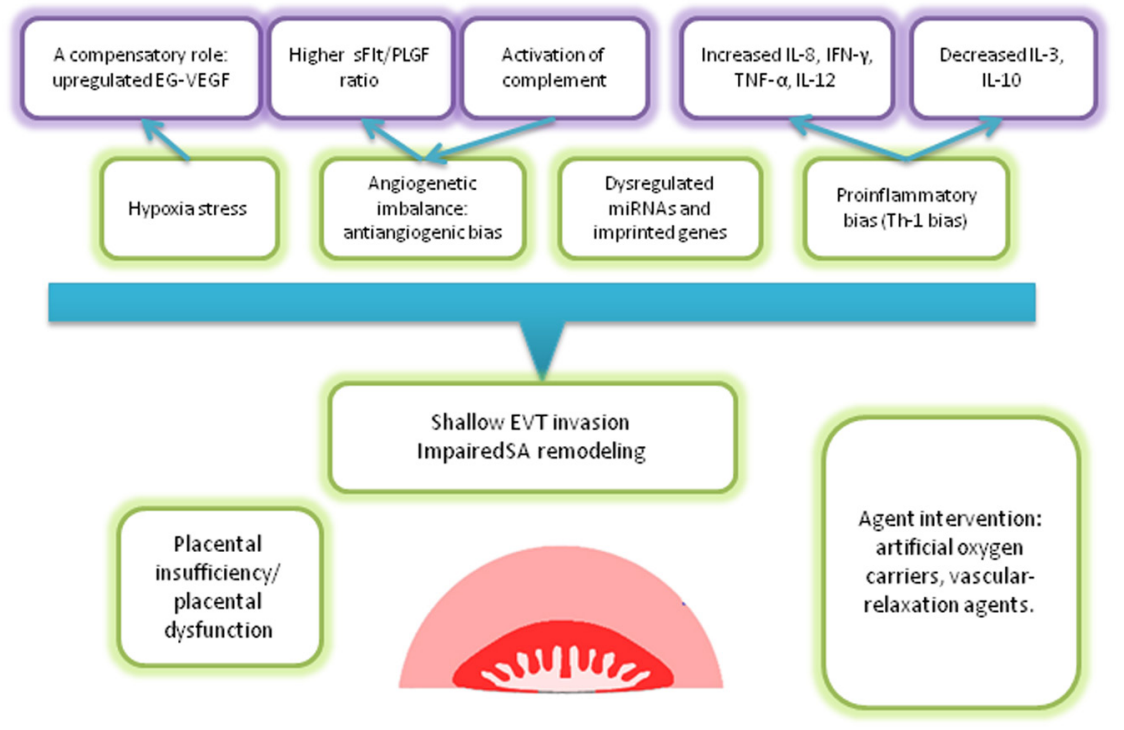

Figure 1 Schematic diagram showing that multiple pathologic states in the placenta of FGR, resulting in placental insufficiency or placental dysfunction. Some interventional strategies targeting to different pathological alterations are also shown. shallow EVT invasion and is a major factor leading to FGR (Genbacev et al. 1997, James et al. 2006). In first trimester villous explants, hypoxia induces the expression of an E3 ubiquitin ligase, Mcl-1 ubiquitin ligase E3 (MULE), through hypoxia-inducible factor 1-alpha (HIF-1 $\alpha)$ and promotes the development of FGR. HIF- $1 \alpha$ levels are elevated in the placenta of FGR and further increase MULE expression, promoting trophoblast apoptosis by targeting the pro-survival Bcl-2 family member, Mcl-1 (Rolfo et al. 2012). Compared to normoxic chick embryos, the heart of hypoxic chick embryos showed left ventricular (LV) dilatation, loss of ventricular wall mass and increased number of apoptotic cardiomyocytes. Cardiomyopathy caused by embryonic hypoxia was found to be persistent in adult animals as well (Tintu et al. 2009).

Soluble fms-like tyrosine kinase-1 (sFlt-1), a soluble truncated variant of the type 1 VEGF receptor (Flt-1) is produced and secreted from the placenta to the maternal circulation. sFlt-1 binds to pro-angiogenic factors VEGF and PLGF and reduces their bioavailability. Thus, the most seriously dysfunctional placentas produce extremely high amounts of sFlt- 1 from the earliest stages of pregnancy. Serum of early-onset preeclampsia patients have significantly higher sFlt-1/PGF ratio as compared with controls (Herraiz et al. 2015) (Fig. 1). Adenosine deaminase (ADA) irreversibly degrades adenosine, a regulator of cellular response to hypoxia, energy depletion and tissue damage. Iriyama and coworkers generated ADA-deficient mice with placenta that lacked ADA and showed that elevated placental adenosine was associated with significantly decreased fetal and placental weights, and impaired vasculature in the labyrinth zone. This was partly because of the elevated Flt mRNA in the placenta and sFlt- 1 in maternal circulating. These results indicate an adverse impact of elevated placental adenosine on the fetus because of its ability to impair placental vasculature (Iriyama et al. 2015).

In FGR, during third trimester, endocrine glandderived vascular endothelial growth factor (EG-VEGF), a novel growth factor secreted by placenta, is significantly upregulated in the placenta and circulating maternal serum. EG-VEGF interacts with prokineticin receptor (PROKR1), stimulates proliferation of $\mathrm{CT}$ and increases placental vascularization (Brouillet et al. 2013, Murthi et al. 2015). During the first trimester, placental expression of EG-VEGF is of vital importance as it creates a physiological hypoxic environment because of the production of functional trophoblast shells and plugs. However, by the end of the first trimester of pregnancy, elevated placental expression of EG-VEGF is deleterious as it inhibits the switch to normoxia in the placenta. Thus, elevated expression of EG-VEGF is considered a cause of FGR. In addition, EG-VEGF is induced by other predisposing factors causing FGR, such as hypoxia. Consequently, the role of EG-VEGF in FGR is still controversial and further studies are required to determine whether EG-VEGF/PROKR deregulation is a cause or consequence of FGR. In conclusion, angiogenesis is considered a necessary process for placentation, which is regulated by the balanced action of pro- and anti-angiogenic factors. In FGR, normal angiogenesis is disrupted because of impaired spiral artery (SA) remodeling in the placenta resulting in insufficient blood flow to the fetus and an aberrant maintenance of homeostasis under hypoxic conditions.

\section{Modulation of fetal growth in FGR by aberrant inflammation and interaction between decidual natural killer (dNK) cells and EVT}

FGR is characterized by altered maternal inflammation mediated by specific cytokines. A study group 
stimulated peripheral blood mononuclear cells (PBMC) with trophoblast (JEG cells) antigens and compared the cytokine profile of maternal lymphocytes between normal pregnancy and FGR group, and FGR group with and without placental insufficiency. Compared to the normal group, FGR group with placental insufficiency showed a stronger pro-inflammatory bias that was characterized by enhanced levels of pro-inflammatory cytokines interleukin-8 (IL-8), interferon gamma (IFN- $\gamma$ ) and tumor necrosis factor-alpha (TNF- $\alpha$ ), and decreased levels of anti-inflammatory cytokines IL-13 and IL-10. FGR group with placental insufficiency indicated a possible pro-inflammatory Th1-bias as seen from the elevated levels of IL-12, a Th1-inducing cytokine, than the FGR group without placental insufficiency (Raghupathy et al. 2012). A murine FGR model induced by multiple injections of antiphospholipid antibodies (aPLs) and mediated by Fc $\gamma$-receptor, revealed augmented levels of TNF- $\alpha$ in maternal plasma, deficient interstitial EVT invasion, impaired spiral artery remodeling and elevated placental nitrosative stress. In addition, deficient trophoblast invasion was associated with enhanced infiltration of macrophages around the spiral arteries with a subsequent increase in TNF- $\alpha$, resulting in the regulation of trophoblast motility and migration (Kawaguchi et al. 2012, Cotechini et al. $2014 a, b)$. FGR associated with antibody-dependent acquired immune response is frequently caused by diverse prenatal congenital infections. Some of these infections are caused by Toxoplasma gondii, rubella, cytomegalovirus (CMV), herpes simplex virus (HSV), Varicella-zoster virus (VZV) and Treponema (Longo et al. 2014). Among these, FGR caused by Porphyromonas gingivalis is well studied. $P$. gingivalis infects the periodontal tissue causing periodontitis. The infection activates the maternal immune and inflammatory responses, characterized by elevated levels of Th1-type cytokines, namely, TNF- $\alpha$, IFN- $\gamma$ and IL-2, and reduced levels of Th2-type cytokine IL-10 in the maternal serum, indicating a shift from placental anti-inflammatory Th2- to pro-inflammatory Th1-type of immune response (Lin et al. 2003a,b).

Normal pregnancy is considered a controlled systemic inflammatory state, as pregnant women have to maintain maternal-fetal immune tolerance (tolerance to non-self-antigens of the fetus). Pregnancy complications are often associated with complement activation, a component of the innate immune system. Frequent deposition of complement component $4 \mathrm{~d}$ (C4d) in syncytiotrophoblast was detected in preeclampsiaFGR patients consistent with maternal vascular underperfusion (MVU) (Kim et al. 2015). Complement activation causes dysregulation of angiogenic factors required for normal vascularization leading to vascular underperfusion. In vitro, complement activation triggers the release of sFlt1 in human monocytes (Girardi et al. 2006). BPH/5, a mouse model with mild hypertension, revealed abnormal placentation, FGR, excessive $\mathrm{C} 3$ deposition and neutrophil infiltration in the ectoplacental cone at E6.5 and E8.5 respectively, consistent with reduced levels of VEGF in the placenta and enhanced levels of TNF- $\alpha$ released by neutrophils (Gelber et al. 2015). In addition, activation of mouse maternal innate immune system by intravenous administration of polyinosinic-polycytidylic acid (poly(I:C)), a nonpathogenic antigen, caused cerebellar neuropathology and behavioral abnormalities in the offspring, which were mediated by an increased IL-6 signaling in the placenta (Wu et al. 2017).

The decidua basalis is the main tissue site where cells from two individuals intermingle. It is differentiated from the endometrium and is characterized by the presence of EVT and a diverse population of leucocytes, such as dNK cells, decidual macrophages (dM $\phi)$ and decidual T cells (dT) (Vesce et al. 2014). The decidua basalis is involved in implantation and placental development. This process is partly mediated by the close interaction between dNK cells and decidual EVT which is brought about by the action of natural killer cell receptors (NKR) and major histocompatibility complex (MHC) on their respective cell surfaces (Colucci et al. 2011). EVT migrating through deciduas can interact with decidual leukocytes and are specialized cells expressing human leukocyte antigen-G+ (HLA-G+). An in vitro co-culture model demonstrated that human EVT could transform CD4+ $\mathrm{T}$ cells to $\mathrm{CD} 4+\mathrm{CD} 25^{\mathrm{H}} \mathrm{FOXP} 3+\mathrm{CD} 45 \mathrm{RA}+$ resting regulatory $\mathrm{T}$ cells (Treg), thereby protecting the foreign fetal tissues from the maternal immune system (Tilburgs et al. 2015). Significantly reduced proportion of $d N K$ cells were found in the human placentas obtained from pregnancies complicated by FGR, compared to control cases (Eide et al. 2006, Williams et al. 2009). Compared to peripheral blood NK cells, dNK cells exhibit distinct phenotypes characterized by the presence of predominant CD56 marker and enhanced expression of certain cell surface receptors including leukocyte immunoglobulin-like receptor B1 (LILRB1), killer-cell immunoglobulinlike receptors (KIRs), NKp46, NKG2D and NKp30, and sphingosine-1-phosphate receptor-5 (S1PR5) (EI Costa et al. 2009). The behavior and function of dNK cells are regulated by the above-mentioned cell surface receptors in human (Fig. 2). Inhibition of S1P-S1PR5 pathway significantly decreases the expression of VEGF and prevents trophoblast migration induced by $\mathrm{dNK}$ cells (Zhang et al. 2013). The expression of the receptors is affected by the decidual microenvironment, namely, a steep decrease in the oxygen gradient from arteries to the intervillous space. In addition, such relative hypoxic environment regulates the EVT invasion-promoting capacity of dNK cells. Increased trophoblast invasion and network formation was associated with higher expression of the activating receptor NKG2D and secretion of invasion-promoting factors by dNK cells 


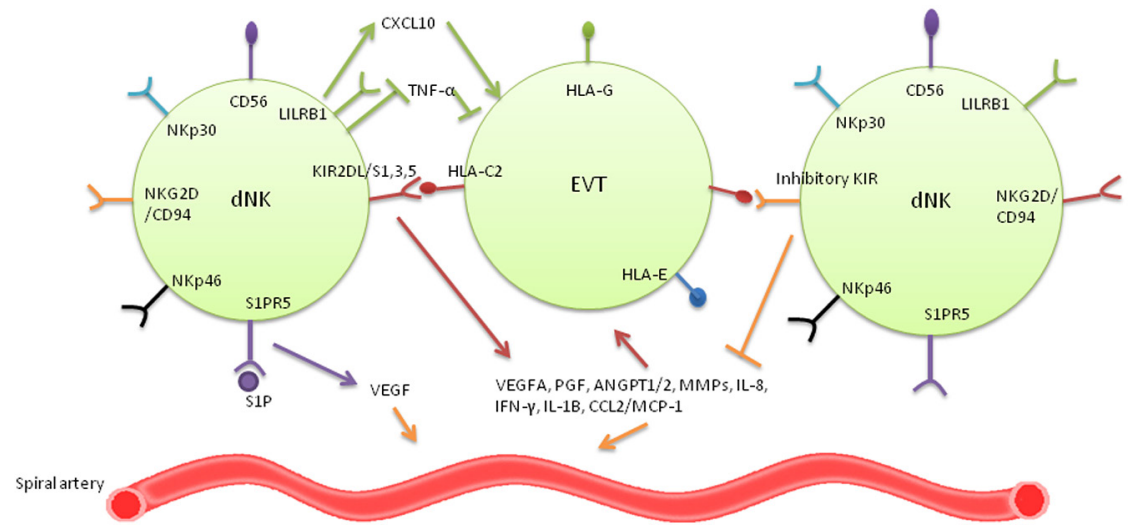

Figure 2 A close interaction between dNK cells and decidual EVT through NKR and MHC. EVT express human leukocyte antigen class I ligands (HLA-E, HLA-G, and HLA-C), recognized by receptors on $\mathrm{dNK}$, such as CD94/NKG2, LILR, and KIR. Activating of S1P-S1PR5 pathway increases the expression of VEGF by dNK cells. Increased LILRB1 binding capacity are related to reduced expression of TNF- $\alpha$ and high expression of CXCL10. Binding frequency of inhibitory or activating KIR to HLA-C2 leads to decreased or increased secretion of cytokines, regulating angiogenesis and invasion of EVT.

cultured in $10 \%$ oxygen, rather than those cultured in 3 and 20\% oxygen (Wallace et al. 2014). These results signify the role of oxygen concentration in the regulation of interaction between EVT and dNK cells.

The interaction between dNK cells and EVT regulates EVT invasion and spiral artery remodeling (Ain et al. 2003, 2004, Wallace et al. 2013). EVT express human leukocyte antigen class I ligands (HLA-E, HLA-G, and $\mathrm{HLA}-\mathrm{C}$ ) that are recognized by dNK cell surface receptors, such as CD94/NKG2, LILR and KIRs. Of these ligands and receptors, KIR and HLA-C genes encoding the KIR/HLA-C system are highly polymorphic. Thus, particular combinations of maternal KIR and fetal HLA-C, which could lead to birth weight difference, characterize each pregnancy. Accordingly, binding of the strongly inhibitory KIR to HLA-C2 inherited from the father leads to reduced secretion of cytokines from dNK cells, such as VEGF-A, PGF, angiopoietin-1 (ANGPT1), ANGPT2, MMPs, IL-8, IFN- $\gamma$, IL-1 $\beta$ and chemokine ligand 2 (CCL2/MCP-1), further causing low birth weight (Lima et al. 2014). Alternatively, activating KIR2DS1 together with fetal HLA-C2 is associated with increased birth weight (Fig. 2). Thus, maintenance of normal birth weight is dependent on the frequency of combination between activating or inhibitory KIR and HLA-C2 (Lash et al. 2011, Robson et al. 2012, Xiong et al. 2013, Moffett et al. 2015). First trimester of pregnancy with high uterine artery Doppler resistance index (RI), a high risk parameter for FGR, is associated with reduced number of $\mathrm{dNK}$ cells expressing activating KIR2DL/S1,3,5 and LILRB1 receptors, and reduced expression of HLA-C and HLA-G receptors on EVT in decidual tissue. dNK cells with decreased LILRB1 binding capacity showed higher expression of TNF- $\alpha$ and lower expression of CXCL10 (Moffett \& Colucci 2015, Wallace et al. 2015). Together, these results suggest a pro-inflammatory nature of FGR placenta that causes placental damage and dysregulation of angiogenic factors manifested by complement deposition and placental underperfusion. Specifically, cytokines secreted by decidual immune cells, namely,
dNK cells, modulate the behavior of EVT through antigen-antibody interaction. This is influenced by the decidual oxide environment, which eventually influences the birth weight.

\section{Dysregulated microRNAs in FGR}

microRNAs (miRNAs) are small (contains approximately 22 nucleotides), non-coding, single-stranded RNAs that function in gene silencing by targeting mRNAs at the post-transcriptional level. In a canonical way, miRNAs are first transcribed by RNA polymerase II. Two enzymes, DROSHA and DICER, process pri-miRNA to pre-miRNA and pre-miRNA to mature miRNA in the nucleus and cytoplasm respectively. Mature miRNAs are then transferred to an argonaute containing RNA inducing silencing complex (RISC) to silence targeted genes (Connerty et al. 2015).

Small non-coding RNAs are expressed in a tissuespecific manner and have emerged as major regulators of cellular processes involved in developmental biology, physiology, and pathology of the placenta, with potential clinical applications. The orchestrated regulation of miRNAs expressed in the placenta is important for placental morphology, structure and function. miRNA-21 enhances cellular proliferation, migration and invasion in HTR-8/SVneo immortalized trophoblast cells by altering the downstream targets, namely, by decreasing the expression of phosphatase and tensin homolog (PTEN), resulting in reduced levels of phosphorylated AKT (Chaiwangyen et al. 2015).

Most miRNAs specifically those expressed in human placenta are derived from two miRNA clusters, the chromosome 14-miRNA cluster (C14MC) and the chromosome 19-miRNA cluster (C19MC). Although C14MC produces many groups of miRNAs in the placenta, most of them are considered nonfunctional and the function of others remain unknown (Mouillet et al. 2015). Paternally inherited C19MC miRNAs are primate-specific and are the most abundant miRNAs in the human placenta and in the sera of pregnant women. 
Interestingly, higher expression of C19MC miRNAs is seen in villous trophoblasts than in invasive EVT. This is consistent with an in vitro observation, wherein, forced expression of C19MC miRNAs attenuated the migration of human EVT. The effects were mediated by C19MC miRNAs through their target genes associated with invasion, such as CXCL6, NR4A2 and FOXL2 (Xie et al. 2014). In addition, up-regulation of circulating C19MC microRNAs in the first trimester could predict the subsequent onset of gestational hypertension (Hromadnikova et al. 2014). However, Masuzaki and coworkers demonstrated that there was a significant decrease in certain placental-specific miRNAs located on C19MC in pregnancies complicated by FGR indicating that FGR may be associated with this downregulation. Nevertheless, no significant changes in the expression level of these placental-specific miRNAs were observed between the maternal plasma in FGR and normal pregnancies and the reason behind it still remains unknown (Higashijima et al. 2013).

The pathogenesis of FGR is related to dysregulation of miRNAs. The expression of miRNA-141 is elevated in the placenta of FGR pregnancies and is of high diagnostic value. miRNA-141 contributes to FGR by downregulating its target genes, E2F3 and PLAG1. miRNA-141 decrease the mRNA level of E2F3 and the mRNA and protein levels of PLAG1 (Tang et al. 2013). Li and coworkers reported enhanced expression of miRNA-424, a hypoxiaregulated miRNA, in the placenta of women with FGR. Compared to controls, the mRNA and protein levels of two of its target genes, mitogen-activated protein kinase 1 (MEK1) and fibroblast growth factor receptor 1 (FGFR1) in the placenta of women with FGR were significantly reduced. Since FGFR1 mediates the functions of VEGF, it is possible that increased miRNA-424 contributes to FGR by affecting the normal vascularity in the placenta (Huang et al. 2013). Significantly enhanced levels of a group of hypoxia-induced miRNAs are seen in the maternal blood of women diagnosed with FGR, suggesting increased expression and secretion of these miRNAs under hypoxic conditions in the placenta during FGR pathogenesis (Whitehead et al. 2013).
Several miRNAs have been demonstrated to regulate trophoblast invasion and migration through diverse downstream signaling pathways. miRNA$135 \mathrm{~b}$ mediates low oxygen-induced reduction of extravillous trophoblast-derived HTR-8/SVneo cell invasion by inhibiting its target gene CXCL12, an invasion-promoting factor (Tamaru et al. 2015). MicroRNA-155 inhibits migration of human HTR-8/ SVneo cell by downregulating cyclin D1 (Dai et al. 2012). miRNA-204 suppresses the invasion of BeWo cells by reducing the expression of its target gene MMP9 (Yu et al. 2015). miR-125b-1-3p inhibits trophoblast cell invasion by targeting S1PR1 in HTR8/SV neo cells (Li et al. 2014a). miR-210 inhibits trophoblast invasion in primary EVT cells partly through extracellular signal regulated kinase (ERK) signaling (Anton et al. 2013). miRNA-144 inhibits human trophoblast cell invasion by inhibiting titin and by subsequently reducing the expression of ERK1/2 and the activity of MMP2/9 (Liang et al. 2014). miR-29b inhibits the invasion and angiogenesis of trophoblast cells by inhibiting its target genes, myeloid cell leukemia sequence 1 (MCL1), MMP2, VEGF-A and ITGB1 (integrin $\beta 1$ ) genes (Li et al. 2013). miRNA-15b inhibits the invasion of HTR8/ SVneo cells and the proliferation and tube formation of HUVECs by targeting the protein-encoding sequence of AGO2 mRNA, the effect of which on trophoblast cell invasion is determined by siRNA specific to AGO2. In an aberrant inflammatory condition mimicked by adding LPS to HTR8 cells, an increase of miR-15b expression mediated by LPS receptor TLR4 was seen which was consistent with the measured increased secretion of sFlt (Yang et al. 2016) (Fig. 3). This study indicates that the negative feedback loops between miRNA and AGO2 might play an important role in regulating the placentation process during the pathogenesis of FGR.

In contrast to the above-mentioned functions of miRNAs, miR-376c promotes migration and invasion of human HTR-8/SVneo cells by targeting Nodal and transforming growth factor- $\beta$ (TGF- $\beta$ ) signaling. miR$376 \mathrm{c}$ targets activin receptor-like kinases ALK5 and $A L K 7$, encoding type I receptor for TGF- $\beta$ and Nodal
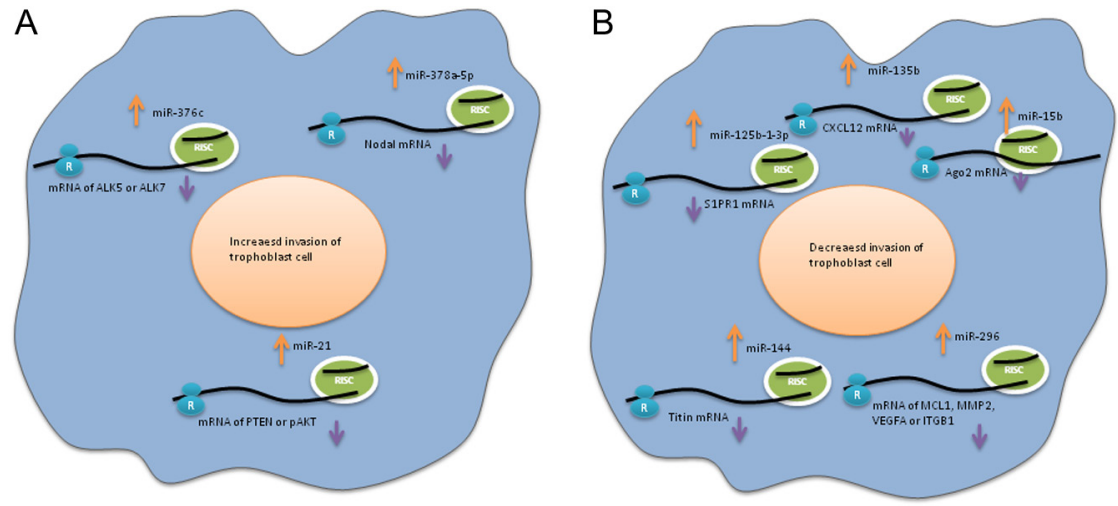

Figure 3 miRNAs linked to invasion of trophoblast cells. (A) Showing that three miRNAs are found to be able to promote invasion of trophoblast cells by degrading respective mRNAs; (B) showing that five miRNAs are found to decrease invasion of trophoblast cells by degrading respective mRNAs. 
respectively, thereby decreasing their expression (Fu et al. 2013). miR-378a-5p promotes trophoblast cell migration and invasion partly by targeting Nodal (Luo et al. 2012) (Fig. 3). Although the association of the above-mentioned miRNAs with FGR has not been investigated, there is a great possibility that these miRNAs are dysregulated in the placenta or plasma of pregnancies complicated by FGR, as impaired trophoblast invasion and/or migration is a primary cause of FGR. The validity of these altered miRNAs in maternal blood from pregnancies complicated by FGR, as a predictor of FGR, warrants further investigation.

\section{Imprinted genes and epigenetic changes are involved in the control of birth weight and FGR pathogenesis}

In mammals, mounting evidence indicate the role of imprinted genes in growth-related functions. Genomic imprinting is an epigenetically driven phenomenon that results in the preferential silencing of a copy of an autosomal gene while the other copy is expressed (Hutter et al. 2010). Imprinted genes that are exclusively expressed in the placenta play a role in the distribution of maternal resources to the fetus (Lambertini et al. 2011). According to the genetic conflict theory of imprinting, maternally imprinted genes that are paternally expressed, such as Igf2, Peg1/Mest and Peg3, promote fetal growth, while paternally imprinted genes that are maternally expressed, such as H19, Igf2r, Cdkn1c, Phlda2 and Grb10, act as growth suppressors (Miguel Constância et al. 2002, Constancia et al. 2005, Tunster et al. 2011, Janssen et al. 2016) (Fig. 4). The disruption of paternally silenced gene Grb10 in mice leads to overgrowth of both, the embryo and the fetus, because of modulation of placental size and efficiency in an Igf2-independent way (Charalambous et al. 2003, 2010). A mouse model overexpressing Phlda2 exhibits late-onset and asymmetric restricted placental and fetal growth. In humans, placental PHLDA2 expression was significantly higher in pregnancies diagnosed with reduced fetal movements (RFM) resulting in the delivery of a growth restricted infant compared with a normal birth weight infant (Janssen et al. 2016).

To analyze the impact of imprinted genes on birth weight, a study group investigated the association between the expression of 108 established and putative imprinted genes expressed in human placenta and birth weight. Nine imprinted genes were positively associated with large for gestational age (LGA) status, including MEST, BLCAP, H19, NDN, PLAGL1, DLK1, IGF2, MEG3 and NNAT, in an order of decreased odds ratio. MEST expression was negatively associated with a risk of SGA status, suggesting it as a novel biomarker for analyzing postnatal health outcomes (Kappil et al. 2015). Another study group found four downregulated genes (CDKAL1, DHCR24, PLAGL1 and ZNF331) and five upregulated genes (CCDC86, ILK, NNAT, PEG10 and PHLDA2) in the FGR placentas of human. Among them, PLAGL1 and ZNF331 were both paternally expressed genes and are in agreement with the 'parental conflict' theory. Two other genes (NNAT and PEG 10) elevated in FGR placenta were paternally expressed, indicating that not all imprinted genes fit the 'parental conflict' theory (Diplas et al. 2009). Among these separate imprinted genes, paternally expressed PLAGL1 seems to mediate a gene network for growth. As a transcription activator, PLAGL1 binds to the H19 39ems to mediate a ge IGF2 and H19, and has a positive correlation with several growth-related genes, including IGF2, H19, SLC2A4 and PPARR1. Interestingly, expression of PLAGL1 shows gender differences in FGR placenta. Total PLAGL1 expression was significantly lower in the placenta of FGR girls than those of boys. This difference was considered to be linked to the hormonal differences between the two sexes (IglesiasPlatas et al. 2014). Imprinted genes are involved in the regulation of placental development due to their effect on the trophoblast cell function. By silencing PEG10 in trophoblast cells, Meng and coworkers demonstrated that PEG10 could enhance human trophoblast proliferation, differentiation and invasion, the latter

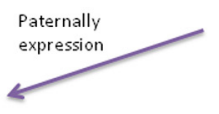

Maternally imprinted genes: Igf2, Peg1/Mest, Peg3

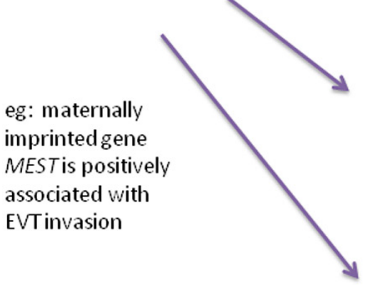

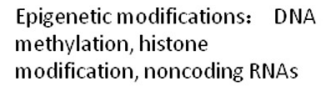
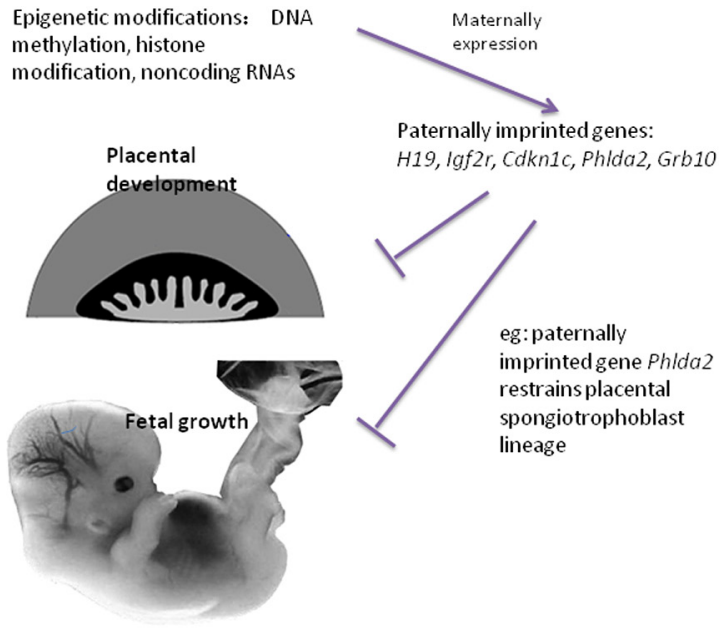

P lafar Cdkn1c Phldaz, Grb10
Figure $4 \mathrm{~A}$ diagram showing a genetic conflict theory of imprinting in mice. Imprinted genes regulated by epigenetic modifications play important roles in placental development and fetal growth. Maternally imprinted genes which are paternally expressed could promote placental development and fetal growth, while paternally imprinted genes which are maternally expressed play a contradictory role. 
was mediated by the up-regulation of MMP-2, MMP-9 and TIMP-1 (Chen et al. 2015). Significantly decreased invasive ability and migration were observed in EVT by knocking down the maternally imprinted gene MEST in HTR8/SVneo cells. This was partly because of the downregulation of the proteins $\mathrm{N}$-cadherin and Vimentin (Peng et al. 2016). Paternally imprinted gene Ph/da2 restrained the placental spongiotrophoblast lineage and inhibited the corresponding hormone production in mice (Tunster et al. 2016).

Changes in epigenetic modifications contribute to stable alterations in gene expression. Imprinted genes are associated with multiple layers of epigenetic regulation, including DNA methylation at differentially methylated regions (DMRs) and histone modifications, resulting in monoallelic expression (Weaver \& Bartolomei 2014). IGF2 is one of the well-studied maternally imprinted genes expressed in maternal, fetal and placental tissues during early pregnancy contributing to fetal growth. Significantly decreased IGF2 mRNA levels were observed in the human placentas from pregnancies complicated by FGR. This was attributed to altered DNA methylation and relaxation of imprinting (Koukoura et al. 2011a). In a FGR mouse model manipulated by caloric restriction, the expression of glucose transporter, Glut3, a predominant isoform of trans-placental glucose transporter, was decreased in the placentas compared to the controls. This was partly due to the increased methylation of CpG island in the promoter of glut3 gene and a series of epigenetic modulation, including enhanced MeCP2 binding to the CpG island, enhanced recruitment of histone deacetylase 2, and decreased Sp1 binding to the CpG island (Ganguly et al. 2014).

A recent study illustrated the relationship between epigenetic modifications and birth weight in human placenta. 5-Methylcytosine $(5 \mathrm{mC})$ enrichment at IGF2 DMRO and KvDMR, a CpG island located on CDKN1C gene, was independently and positively related to birth weight. 5-hydroxymethylcytosine (5hmC) enrichment within the $\mathrm{H} 19$ gene body was also positively related to birth weight, although no significant relationship was found at any of the regions between the mRNA levels of IGF2 and CDKN1C and $5 \mathrm{mC}$ or $5 \mathrm{hmC}$ (Piyasena et al. 2015). The H19 imprinted gene clustered with the IGF2 gene on human chromosome $11 \mathrm{p} 15.5$, is co-controlled with IGF2 by differential methylation at an imprinting control region ICR1, located between IGF2 and H19. DNA methylation at ICR1 on the paternal allele is permissive for IGF2 gene expression. In contrast, the unmethylated maternal ICR1 activates H19 expression. The placenta from women diagnosed with FGR showed significantly enhanced expression of $\mathrm{H} 19$ and decreased methylation in its promoter, which is consistent with a notion that $H 19$ produces an untranslated RNA that suppresses growth (Koukoura et al. 2011b, Piyasena et al. 2015). Although DNA methylation at ICR1 is proven to affect IGF2 expression, the methylation level at ICR 1 is not significantly reduced in FGR placentas (Guo et al. 2008, Bourque et al. 2010). Together, these results indicate the important role played by imprinted genes that are highly expressed in the placenta and their epigenetic modifications in FGR pathogenesis.

\section{Animal models and experimental intervention in FGR}

In FGR, early delivery is the only intervention to reduce the risk of severe maternal complications and/ or stillbirth of the baby. However, early delivery itself is associated with increased risk of neonatal mortality and morbidity. Therefore, there is a pressing need to develop new and effective treatments that can prevent or treat pregnancy complications like FGR (Cottrell \& Sibley 2015). Developing new therapies for FGR requires the use of animal models to test the efficacy and safety of the therapy, and the characteristics of pregnancy in the particular animal model should be taken into consideration (Swanson \& David 2015). Different types of animal models are used to study different types of human FGR. Asymmetrical FGR is studied in an animal model manipulated by knocking out the NOS gene. These animals show a phenomenon of 'brain sparing', a compensatory process wherein the fetus redistributes its cardiac output to maximize oxygen and nutrient supply to the brain at the expense of other structures such as the liver, abdomen and long bones (Cohen et al. 2015, Swanson \& David 2015). Guinea pig shares several characteristics with humans. Pregnant guinea pigs exposed to hypoxia are considered an ideal model for placental vascular insufficiency. This animal model of placental hypoxia manifests certain abnormal placental developmental phenotypes, including increased trophoblast proliferation, and decreased migration and invasion of trophoblast into the spiral arteries (Thompson et al. 2016). In addition, the pregnant $\mathrm{DBA} / 2$ J male mice-mated $\mathrm{CBA} / \mathrm{J}$ or its substrain $\mathrm{CBA} / \mathrm{CaH}$ female mice spontaneously develops FGR with placental histopathology, such as significantly decreased proportion of labyrinth, higher proportion of spongiotrophoblast and decreased placental efficiency measured as a ratio of placental weight to fetal weight. Importantly, this FGR animal model is ideal for the assessment and development of new therapeutics, since animal models created by genetic, surgical and pharmacological manipulation inadvertently introduce confounding factors when utilized for the same. Overall, an ideal animal model for studying the pathology of human placental insufficiency should recapitulate the changes in the placental morphology, alterations in genomic expression profile, cytokine milieu and transporter function (Habli et al. 2013). 
Numerous agents ameliorate FGR by targeting different pathological alteration, including decreased oxygen supply to fetus and impaired remodeling of spiral arteries. The application of artificial oxygen carriers, a kind of hemoglobin vesicles, which are nano-scale sized and blood-type antigens free, in a rat preeclampsia model induced by continuous administration of the NO synthetase inhibitor was demonstrated to reduce the hypoxic status of the placenta and fetus by supplying oxygen through the pathological narrow spiral arteries (Li et al. 2015). A set of vascular-relaxation agents, including antioxidant 4-hydroxy-2,2,6,6-tetramethylpiperidin-1-oxyl (Tempol) (Stanley et al. 2012), Ligustrazine (Li et al. 2014b), Resveratrol (Poudel et al. 2013), and Sildenafil citrate (Dilworth et al. 2013), ameliorated blood rheological status and increased fetal weight in different FGR animal models (Fig. 1). However, considering the uncertainty regarding the safety and side effects of these agents in pregnant women, they do not find application in the clinic until further studies testify their efficacy and safety for pregnant women.

\section{Prediction of FGR}

In many cases, effective treatment strategy depends on timely diagnosis. Therefore, it is of great importance to develop a predictor for FGR with high specificity and sensitivity. Diverse pathological alterations play a predominant role in different gestations and hence, different predictive biomarkers are used to predict FGR in different gestations. Since placenta has an essential role in determining the outcome of pregnancy, detection of placental-derived factors in maternal blood has been suggested as a means to predict the fetal outcome of pregnancy. In the first trimester of pregnancy, increased maternal circulating IGFBP-4 is considered as a promising biomarker of FGR. It reflects an abnormally high IGFBP-4 protein content in the placental bed, consistent with the reduction of IGF-2 bioavailability. Importantly, it has a higher predictive value than many other biomarkers alone, including circulating human chorionic gonadotropin (b-hCG), $\alpha$-fetoprotein (AFP), ADAM-12 (a disintegrin and metalloprotease-12), placental protein 13 (PP-13), soluble endoglin and s-Flt1 (Qiu et al. 2012). Pregnancy-associated plasma protein A (PAPP-A), a pregnancy related protein mediating IGFBP-4 degradation, measured in maternal serum in the first trimester, is reported to have a predictive value for FGR among Chinese population, especially severe FGR (Lo et al. 2015, 2016, Hansen et al. 2016). A prospective survey among low risk Asian population in the first trimester showed increased uterine artery pulsatility index (UPI) measured by uterine artery Doppler as the most important marker for FGR, compared with other biomarkers in maternal serum, such as PAPP-A and free $\beta$-hCG (Kumar et al. 2016). In clinically high-risk pregnancies, prediction of adverse perinatal outcomes using placental function testing is more effective in the second compared to the first trimester (Costa et al. 2008).

In the second trimester, sFlt1 can strongly predict severe adverse pregnancy outcome (APO) during 12-15 weeks of gestation among pregnant women with systemic lupus erythematosus (SLE) and/ or antiphospholipid antibodies (APL) syndrome. Nevertheless, the combination of sFlt1 and PGF is the best predictive biomarker of APO during 16-19 weeks of gestation with low PGF and high sFlt1 among the same subjects (Kim et al. 2016). Increased expression of activating transcription factor-3 (ATF3) messenger RNA, a negative regulator of inflammation, was detected in

Table 1 Predictive biomarkers for FGR in different studies.

\begin{tabular}{|c|c|c|c|c|c|c|}
\hline Biomarker & Function & Site of detection & Time of detection & $\begin{array}{l}\text { Method of } \\
\text { detection }\end{array}$ & Application & Reference \\
\hline IGFBP-4 & $\begin{array}{l}\text { Reducing the } \\
\text { bioavailability of IGF-2 }\end{array}$ & Maternal blood & The first trimester & ELISA & Predicting FGR & Qiu et al. (2012) \\
\hline PAPP-A & $\begin{array}{l}\text { Mediating degradation of } \\
\text { IGFBP-4 }\end{array}$ & Maternal blood & The first trimester & ELISA & Predicting FGR & $\begin{array}{l}\text { Lo et al. (2015, 2016), } \\
\text { Hansen et al. (2016) }\end{array}$ \\
\hline UPI & $\begin{array}{l}\text { Reflecting utero-placental } \\
\text { blood supply }\end{array}$ & uterine & The first trimester & $\begin{array}{l}\text { Uterine artery } \\
\text { Doppler }\end{array}$ & Predicting FGR & Kumar et al. (2016) \\
\hline $\begin{array}{l}\text { The ratio of } \\
\text { sFlt-1 and } \\
\text { PGF }\end{array}$ & $\begin{array}{l}\text { Reflecting placental } \\
\text { vascular function }\end{array}$ & Maternal blood & The second trimester & ELISA & $\begin{array}{l}\text { Predicting severe } \\
\text { APO }\end{array}$ & Kim et al. (2016) \\
\hline ATF3 mRNA & $\begin{array}{l}\text { A negative regulator of } \\
\text { inflammation }\end{array}$ & Maternal blood & The second trimester & RT-PCR & Predicting FGR & $\begin{array}{l}\text { Lim et al. (2016), } \\
\text { Whitehead et al. } \\
\text { (2016) }\end{array}$ \\
\hline Pentraxin 3 & $\begin{array}{l}\text { Reflecting endothelial } \\
\text { dysfunction in placenta }\end{array}$ & Maternal blood & The third trimester & ELISA & $\begin{array}{l}\text { Differentiating } \\
\text { physiological } \\
\text { SGA from } \\
\text { pathological FGR }\end{array}$ & $\begin{array}{l}\text { Cozzi et al. (2012), } \\
\quad \text { Ibrahim et al. (2015) }\end{array}$ \\
\hline $\begin{array}{l}\text { Complement } \\
\text { C3 }\end{array}$ & $\begin{array}{l}\text { C3 deposition in the } \\
\text { placenta is associated } \\
\text { with placental } \\
\text { insufficiency }\end{array}$ & Placenta & All trimesters & MRI & $\begin{array}{l}\text { Predicting placenta } \\
\text { insufficiency }\end{array}$ & Girardi et al. (2015) \\
\hline
\end{tabular}


maternal blood by RT-PCR at 26-30 weeks' gestation. It was found to be the most promising single biomarker for predicting late-onset FGR, compared to other significantly dysregulated mRNAs encoded by highly expressed genes of the placenta in the maternal blood (Lim et al. 2016, Whitehead et al. 2016).

In the third trimester, pentraxin 3 (PTX3), a C-reactive protein family member expressed in response to inflammatory stimuli is helpful in differentiating growth restricted babies into physiological SGA and pathological FGR. Pregnancies complicated by FGR have higher PTX3 concentrations in the maternal blood than controls. This increase was related to the severity of FGR, since increased PTX3 reflects endothelial dysfunction in the placenta (Cozzi et al. 2012, Ibrahim et al. 2015). A new, non-invasive approach involving binding to the C3 deposited tissue is proposed to predict placental insufficiency and abnormal fetal brain development in a mouse model representing antiphospholipid syndrome (APS). After intravenous injection of anti-complement C3-targeted ultrasmall superparamagnetic iron oxide (USPIO) nanoparticles, which do not affect pregnancy outcome and liver function in the mother and the offspring, they bind to the C3 deposited tissue. This binding is observed as $\mathrm{T} 2$ and $\mathrm{T} 2 *$ relaxation time in magnetic resonance imaging (MRI). C3 deposition in the placenta is associated with placental insufficiency. C3 deposition in the brain is associated with cortical fetal brain abnormalities accompanied by increased anxiety-related behavior after birth. Thus, it is important to investigate whether there is excessive C3 deposition in the placenta and to determine the impaired degree of placentas during all trimesters (Girardi et al. 2015). The biomarkers mentioned above have been summarized in Table 1. Although several biomarkers are used as predictors for placental function and subsequent pregnancy outcome, the definitive predictive value of a biomarker has to be evaluated for exploring the possibility of using it in the clinic. Furthermore, a deeper understanding of the specific pathological alterations is needed. Convenience and feasibility has to be taken into account when translating basic research into clinical application.

\section{Conclusion}

FGR is a complex pathological status that predisposes the baby to a high risk of perinatal morbidity and mortality with long-term effects on neurological behavior and cardiovascular system of the fetus. Although the precise mechanism is still unknown, the adversity in the uterine during fetal development has a profound effect on the fetus. Maternal stress during pregnancy predisposes offspring to sex-biased neurodevelopmental disorder, which mostly occurs in boys (Bronson \& Bale 2016). Placenta is of great importance during the process for it is located at the interface between the fetus and the mother, and plays a role in the exchange of oxygen and nutrients, buffering from deleterious maternal factors. In general, FGR is associated with abnormal placentation and an anti-angiogenic and pro-inflammatory bias. Furthermore, multiple layers of regulation are involved in the pathogenesis of FGR, including interaction between EVT and decidual leukocytes, altered expression of miRNA in placenta and maternal circulation, imprinted genes and their epigenetic modifications, among others. Although it is still unclear how these factors interact with each other to play a causal role in FGR, identifying these factors has helped us have a better knowledge of the physiology of fetal growth and the pathology of FGR. Furthermore, it is imperative to analyze valuable biomarkers and promising agents in a large cohort to examine whether they have a diagnostic/predictive or curative value, making it possible to recognize and treat FGR as early as possible, and to save the baby from an adverse pregnancy outcome.

\section{Declaration of interest}

The authors declare that there is no conflict of interest that could be perceived as prejudicing the impartiality of the research reported.

\section{Funding}

This work was supported by the National Basic Research Program of China (2012CB944903); the Ministry of Education Program for New Century Excellent Talents in University (NCET-12-0382).

\section{References}

Ain R, Tash JS \& Soares MJ 2003 Prolactin-like protein-A is a functional modulator of natural killer cells at the maternal-fetal interface. Molecular and Cellular Endocrinology 204 65-74. (doi:10.1016/S03037207(03)00125-4)

Ain R, Trinh ML \& Soares MJ 2004 Interleukin-11 signaling is required for the differentiation of natural killer cells at the maternal-fetal interface. Developmental Dynamics 231 700-708. (doi:10.1002/dvdy.20183)

Anton L, Olarerin-George AO, Schwartz N, Srinivas S, Bastek J, Hogenesch JB \& Elovitz MA 2013 miR-210 inhibits trophoblast invasion and is a serum biomarker for preeclampsia. American Journal of Pathology 183 1437-1445. (doi:10.1016/j.ajpath.2013.07.021)

Bale TL 2015 Epigenetic and transgenerational reprogramming of brain development. Nature Reviews Neuroscience 16 332-344. (doi:10.1038/ nrn3818)

Bamberg C \& Kalache KD 2004 Prenatal diagnosis of fetal growth restriction. Seminars in Fetal and Neonatal Medicine 9 387-394. (doi:10.1016/j.siny.2004.03.007)

Biyashev D \& Qin G 2011 E2F and microRNA regulation of angiogenesis. American Journal of Cardiovascular Disease 1 110-118.

Bourque DK, Avila L, Penaherrera M, von Dadelszen P \& Robinson WP 2010 Decreased placental methylation at the H19/IGF2 imprinting control region is associated with normotensive intrauterine growth restriction but not preeclampsia. Placenta 31 197-202. (doi:10.1016/j. placenta.2009.12.003)

Bronson SL \& Bale TL 2016 The placenta as a mediator of stress effects on neurodevelopmental reprogramming. Neuropsychopharmacology $\mathbf{4 1}$ 207-218. (doi:10.1038/npp.2015.231) 
Brouillet S, Murthi P, Hoffmann P, Salomon A, Sergent F, De Mazancourt P, Dakouane-Giudicelli M, Dieudonne MN, Rozenberg P, Vaiman D et al. 2013 EG-VEGF controls placental growth and survival in normal and pathological pregnancies: case of fetal growth restriction (FGR). Cellular and Molecular Life Sciences 70 511-525. (doi:10.1007/s00018012-1141-z)

Burton GJ, Woods AW, Jauniaux E \& Kingdom JC 2009 Rheological and physiological consequences of conversion of the maternal spiral arteries for uteroplacental blood flow during human pregnancy. Placenta $\mathbf{3 0}$ 473-482. (doi:10.1016/j.placenta.2009.02.009)

Chaiwangyen W, Ospina-Prieto S, Photini SM, Schleussner E, Markert UR \& Morales-Prieto DM 2015 Dissimilar microRNA-21 functions and targets in trophoblastic cell lines of different origin. International Journal of Biochemistry and Cell Biology 68 187-196. (doi:10.1016/j. biocel.2015.08.018)

Charalambous M, Cowley M, Geoghegan F, Smith FM, Radford EJ, Marlow BP, Graham CF, Hurst LD \& Ward A 2010 Maternally-inherited Grb10 reduces placental size and efficiency. Developmental Biology 337 1-8. (doi:10.1016/j.ydbio.2009.10.011)

Charalambous M, Smith FM, Bennett WR, Crew TE, Mackenzie F \& Ward A 2003 Disruption of the imprinted Grb10 gene leads to disproportionate overgrowth by an Igf2-independent mechanism. PNAS 100 8292-8297. (doi:10.1073/pnas.1532175100)

Chen H, Sun M, Liu J, Tong C \& Meng T 2015 Silencing of paternally expressed gene 10 inhibits trophoblast proliferation and invasion. PLoS ONE 10 e0144845. (doi:10.1371/journal.pone.0144845)

Cohen E, Baerts W, Alderliesten T, Derks J, Lemmers P \& van Bel F 2015 Growth restriction and gender influence cerebral oxygenation in preterm neonates. Archives of Disease in Childhood: Fetal and Neonatal Edition 101 F156-F161. (doi:10.1136/archdischild-2015-308843)

Colucci F, Boulenouar S, Kieckbusch J \& Moffett A 2011 How does variability of immune system genes affect placentation? Placenta $\mathbf{3 2}$ 539-545. (doi:10.1016/j.placenta.2011.05.001)

Connerty P, Ahadi A \& Hutvagner G 2015 RNA binding proteins in the miRNA pathway. International Journal of Molecular Sciences 1731. (doi:10.3390/ijms17010031)

Constancia M, Angiolini E, Sandovici I, Smith P, Smith R, Kelsey G, Dean W, Ferguson-Smith A, Sibley CP, Reik W et al. 2005 Adaptation of nutrient supply to fetal demand in the mouse involves interaction between the Igf2 gene and placental transporter systems. PNAS 102 19219-19224. (doi:10.1073/pnas.0504468103)

Costa SL, Proctor L, Dodd JM, Toal M, Okun N, Johnson JA, Windrim R \& Kingdom JC 2008 Screening for placental insufficiency in high-risk pregnancies: is earlier better? Placenta 29 1034-1040. (doi:10.1016/j. placenta.2008.09.004)

Cotechini T, Hopman WJ \& Graham CH 2014a Inflammationinduced fetal growth restriction in rats is associated with altered placental morphometrics. Placenta 35 575-581. (doi:10.1016/j. placenta.2014.05.002)

Cotechini T, Komisarenko M, Sperou A, Macdonald-Goodfellow S, Adams MA \& Graham CH 2014b Inflammation in rat pregnancy inhibits spiral artery remodeling leading to fetal growth restriction and features of preeclampsia. Journal of Experimental Medicine 211 165-179. (doi:10.1084/jem.20130295)

Cottrell EC \& Sibley CP 2015 From pre-clinical studies to clinical trials: generation of novel therapies for pregnancy complications. International Journal of Molecular Sciences 16 12907-12924. (doi:10.3390/ ijms160612907)

Cozzi V, Garlanda C, Nebuloni M, Maina V, Martinelli A, Calabrese S \& Cetin I 2012 PTX3 as a potential endothelial dysfunction biomarker for severity of preeclampsia and IUGR. Placenta 33 1039-1044. (doi:10.1016/j.placenta.2012.09.009)

Crispi F, Bijnens B, Sepulveda-Swatson E, Cruz-Lemini M, Rojas-Benavente J, Gonzalez-Tendero A, Garcia-Posada R, Rodriguez-Lopez M, Demicheva E, Sitges M et al. 2014 Postsystolic shortening by myocardial deformation imaging as a sign of cardiac adaptation to pressure overload in fetal growth restriction. Circulation Cardiovascular Imaging 7 781787. (doi:10.1161/CIRCIMAGING.113.001490)

Dai Y, Qiu Z, Diao Z, Shen L, Xue P, Sun H \& Hu Y 2012 MicroRNA-155 inhibits proliferation and migration of human extravillous trophoblast derived HTR-8/SVneo cells via down-regulating cyclin D1. Placenta 33 824-829. (doi:10.1016/j.placenta.2012.07.012)
Dilworth MR, Andersson I, Renshall LJ, Cowley E, Baker P, Greenwood S, Sibley CP \& Wareing M 2013 Sildenafil citrate increases fetal weight in a mouse model of fetal growth restriction with a normal vascular phenotype. PLoS ONE 8 e77748. (doi:10.1371/journal.pone.0077748)

Diplas AI, Lambertini L, Lee M-J, Sperling R, Lee YL, Wetmur J \& Chen J 2009 Differential expression of imprinted genes in normal and IUGR. Epigenetics 4 235-240. (doi:10.4161/epi.9019)

Eide IP, Rolfseng T, Isaksen CV, Mecsei R, Roald B, Lydersen S, Salvesen KA, Harsem NK \& Austgulen R 2006 Serious foetal growth restriction is associated with reduced proportions of natural killer cells in decidua basalis. Virchows Archiv 448 269-276. (doi:10.1007/s00428-0050107-z)

El Costa H, Tabiasco J, Berrebi A, Parant O, Aguerre-Girr M, Piccinni MP \& Le Bouteiller P 2009 Effector functions of human decidual NK cells in healthy early pregnancy are dependent on the specific engagement of natural cytotoxicity receptors. Journal of Reproductive Immunology $\mathbf{8 2}$ 142-147. (doi:10.1016/j.jri.2009.06.123)

Fu G, Ye G, Nadeem L, Ji L, Manchanda T, Wang Y, Zhao Y, Qiao J, Wang YL, Lye S et al. 2013 MicroRNA-376c impairs transforming growth factor-beta and nodal signaling to promote trophoblast cell proliferation and invasion. Hypertension 61 864-872. (doi:10.1161/ HYPERTENSIONAHA.111.203489)

Ganguly A, Chen Y, Shin BC \& Devaskar SU 2014 Prenatal caloric restriction enhances DNA methylation and MeCP2 recruitment with reduced murine placental glucose transporter isoform 3 expression. Journal of Nutritional Biochemistry 25 259-266. (doi:10.1016/j. jnutbio.2013.10.015)

Gelber SE, Brent E, Redecha P, Perino G, Tomlinson S, Davisson RL \& Salmon JE 2015 Prevention of defective placentation and pregnancy loss by blocking innate immune pathways in a syngeneic model of placental insufficiency. Journal of Immunology 195 1129-1138. (doi:10.4049/ jimmunol.1402220)

Genbacev O, Zhou Y, Ludlow JW \& Fisher SJ 1997 Regulation of human placental development by oxygen tension. Science 277 1669-1672. (doi:10.1126/science.277.5332.1669)

Girardi G, Fraser J, Lennen R, Vontell R, Jansen M \& Hutchison G 2015 Imaging of activated complement using ultrasmall superparamagnetic iron oxide particles (USPIO) - conjugated vectors: an in vivo in utero non-invasive method to predict placental insufficiency and abnormal fetal brain development. Molecular Psychiatry 20 1017-1026. (doi:10.1038/mp.2014.110)

Girardi G, Yarilin D, Thurman JM, Holers VM \& Salmon JE 2006 Complement activation induces dysregulation of angiogenic factors and causes fetal rejection and growth restriction. Journal of Experimental Medicine 203 2165-2175. (doi:10.1084/jem.20061022)

Gordijn SJ, Beune IM, Thilaganathan B, Papageorghiou A, Baschat AA, Baker PN, Silver RM, Wynia K \& Ganzevoort W 2016 Consensus definition of fetal growth restriction: a Delphi procedure. Ultrasound in Obstetrics and Gynecology 48 333-339. (doi:10.1002/uog.15884)

Guo L, Choufani S, Ferreira J, Smith A, Chitayat D, Shuman C, Uxa R, Keating S, Kingdom J \& Weksberg R 2008 Altered gene expression and methylation of the human chromosome 11 imprinted region in small for gestational age (SGA) placentae. Developmental Biology 320 79-91. (doi:10.1016/j.ydbio.2008.04.025)

Guttmacher AE, Maddox YT \& Spong CY 2014 The human placenta project: placental structure, development, and function in real time. Placenta 35 303-304. (doi:10.1016/j.placenta.2014.02.012)

Habli M, Jones H, Aronow B, Omar K \& Crombleholme TM 2013 Recapitulation of characteristics of human placental vascular insufficiency in a novel mouse model. Placenta 34 1150-1158. (doi:10.1016/j.placenta.2013.09.011)

Hansen YB, Myrhoj V, Jorgensen FS, Oxvig C \& Sorensen S 2016 First trimester PAPP-A2, PAPP-A and hCGbeta in small-for-gestational-age pregnancies. Clinical Chemistry and Laboratory Medicine 54 117-123.

Herraiz I, Simon E, Gomez-Arriaga PI, Martinez-Moratalla JM, GarciaBurguillo A, Jimenez EA \& Galindo A 2015 Angiogenesis-related biomarkers (sFlt-1/PLGF) in the prediction and diagnosis of placental dysfunction: an approach for clinical integration. International Journal of Molecular Sciences 16 19009-19026. (doi:10.3390/ ijms160819009)

Higashijima A, Miura K, Mishima H, Kinoshita A, Jo O, Abe S, Hasegawa Y, Miura S, Yamasaki K, Yoshida A et al. 2013 Characterization of placenta- 
specific microRNAs in fetal growth restriction pregnancy. Prenatal Diagnosis 33 214-222. (doi:10.1002/pd.4045)

Hromadnikova I, Kotlabova K, Hympanova L, Doucha J \& Krofta L 2014 First trimester screening of circulating C19MC microRNAs can predict subsequent onset of gestational hypertension. PLOS ONE 9 e113735. (doi:10.1371/journal.pone.0113735)

Huang L, Shen Z, Xu Q, Huang X, Chen Q \& Li D 2013 Increased levels of microRNA-424 are associated with the pathogenesis of fetal growth restriction. Placenta 34 624-627. (doi:10.1016/j. placenta.2013.04.009)

Hutter B, Bieg M, Helms V \& Paulsen M 2010 Imprinted genes show unique patterns of sequence conservation. BMC Genomics 11649. (doi:10.1186/1471-2164-11-649)

Ibrahim MI, Ammar EM, Ramy A, Ellaithy MI, Abdelrahman RM \& Elkabarity R 2015 The association between pentraxin 3 in maternal circulation and pathological intrauterine fetal growth restriction. European Journal of Obstetrics and Gynecology and Reproductive Biology 185 1-8. (doi:10.1016/j.ejogrb.2014.11.010)

Iglesias-Platas I, Martin-Trujillo A, Petazzi P, Guillaumet-Adkins A, Esteller M \& Monk D 2014 Altered expression of the imprinted transcription factor PLAGL1 deregulates a network of genes in the human IUGR placenta. Human Molecular Genetics 23 6275-6285. (doi:10.1093/ hmg/ddu347)

Iriyama T, Sun K, Parchim NF, Li J, Zhao C, Song A, Hart LA, Blackwell SC, Sibai BM, Chan LN et al. 2015 Elevated placental adenosine signaling contributes to the pathogenesis of preeclampsia. Circulation 131 730-741. (doi:10.1161/CIRCULATIONAHA.114.013740)

James JL, Stone PR \& Chamley LW 2006 The regulation of trophoblast differentiation by oxygen in the first trimester of pregnancy. Human Reproduction Update 12 137-144. (doi:10.1093/humupd/dmi043)

Jang EA, Longo LD \& Goyal R 2015 Antenatal maternal hypoxia: criterion for fetal growth restriction in rodents. Frontiers in Physiology 6176. (doi:10.3389/fphys.2015.00176)

Janssen AB, Tunster SJ, Heazell AEP \& John RM 2016 Placental PHLDA2 expression is increased in cases of fetal growth restriction following reduced fetal movements. BMC Medical Genetics 17 17. (doi:10.1186/ s12881-016-0279-1)

Jansson T \& Powell TL 2007 Role of the placenta in fetal programming: underlying mechanisms and potential interventional approaches. Clinical Science 113 1-13. (doi:10.1042/CS20060339)

Kadyrov M, Kingdom JC \& Huppertz B 2006 Divergent trophoblast invasion and apoptosis in placental bed spiral arteries from pregnancies complicated by maternal anemia and early-onset preeclampsia/ intrauterine growth restriction. American Journal of Obstetrics and Gynecology 194 557-563. (doi:10.1016/j.ajog.2005.07.035)

Kappil MA, Green BB, Armstrong DA, Sharp AJ, Lambertini L, Marsit CJ \& Chen J 2015 Placental expression profile of imprinted genes impacts birth weight. Epigenetics 10 842-849. (doi:10.1080/15592294.2015.1 073881)

Kaufmann P, Black S \& Huppertz B 2003 Endovascular trophoblast invasion: implications for the pathogenesis of intrauterine growth retardation and preeclampsia. Biology of Reproduction 69 1-7. (doi:10.1095/ biolreprod.102.014977)

Kawaguchi R, Nunomura S, Umehara N, Nikaido T, Huppertz B, Tanaka T \& Ra C 2012 Multiple injections of anti-mouse beta2glycoprotein 1 antibody induce FcRgamma-dependent fetal growth restriction (FGR) in mice. Placenta 33 540-547. (doi:10.1016/j.placenta.2012.03.010)

Kim EN, Yoon BH, Lee JY, Hwang D, Kim KC, Lee J, Shim JY \& Kim CJ 2015 Placental C4d deposition is a feature of defective placentation: observations in cases of preeclampsia and miscarriage. Virchows Archiv 466 717-725. (doi:10.1007/s00428-015-1759-y)

Kim MY, Buyon JP, Guerra MM, Rana S, Zhang D, Laskin CA, Petri M, Lockshin MD, Sammaritano LR, Branch DW et al. 2016 Angiogenic factor imbalance early in pregnancy predicts adverse outcomes in patients with lupus and antiphospholipid antibodies: results of the PROMISSE study. American Journal of Obstetrics and Gynecology 214 108 108.e1-108.e14. (doi:10.1016/j.ajog.2015.09.066)

Koukoura O, Sifakis S, Soufla G, Zaravinos A, Apostolidou S, Jones A, Widschwendter M \& Spandidos DA 2011a Loss of imprinting and aberrant methylation of IGF2 in placentas from pregnancies complicated with fetal growth restriction. International Journal of Molecular Medicine 28 481-487.
Koukoura O, Sifakis S, Zaravinos A, Apostolidou S, Jones A, Hajiioannou J, Widschwendter M \& Spandidos DA 2011b Hypomethylation along with increased $\mathrm{H} 19$ expression in placentas from pregnancies complicated with fetal growth restriction. Placenta 32 51-57. (doi:10.1016/j. placenta.2010.10.017)

Kumar M, Singh S, Sharma K, Singh R, Ravi V \& Bhattacharya J 2016 Adverse fetal outcome: is first trimester ultrasound and Doppler better predictor than biomarkers? Journal of Maternal-Fetal and Neonatal Medicine 10 1-7. (doi:10.1080/14767058.2016.1214709)

Lambertini L, Lee TL, Chan WY, Lee MJ, Diplas A, Wetmur J \& Chen J 2011 Differential methylation of imprinted genes in growthrestricted placentas. Reproductive Sciences 18 1111-1117. (doi:10.1177/1933719111404611)

Lanner F 2014 Lineage specification in the early mouse embryo. Experimental Cell Research 321 32-39. (doi:10.1016/j.yexcr.2013.12.004)

Lash GE, Naruse K, Robson A, Innes BA, Searle RF, Robson SC \& Bulmer JN 2011 Interaction between uterine natural killer cells and extravillous trophoblast cells: effect on cytokine and angiogenic growth factor production. Human Reproduction 26 2289-2295. (doi:10.1093/ humrep/der198)

Li H, Ohta H, Tahara Y, Nakamura S, Taguchi K, Nakagawa M, Oishi Y, Goto Y, Wada K, Kaga M et al. 2015 Artificial oxygen carriers rescue placental hypoxia and improve fetal development in the rat pre-eclampsia model. Scientific Reports 5 15271. (doi:10.1038/srep15271)

Li P, Guo W, Du L, Zhao J, Wang Y, Liu L, Hu Y \& Hou Y 2013 microRNA$29 \mathrm{~b}$ contributes to pre-eclampsia through its effects on apoptosis, invasion and angiogenesis of trophoblast cells. Clinical Sciences $\mathbf{1 2 4}$ 27-40. (doi:10.1042/cs20120121)

Li Q, Pan Z, Wang X, Gao Z, Ren C \& Yang W 2014a miR-125b-1-3p inhibits trophoblast cell invasion by targeting sphingosine-1-phosphate receptor 1 in preeclampsia. Biochemical and Biophysical Research Communications 453 57-63. (doi:10.1016/j.bbrc.2014.09.059)

Li S-W, Ling Y, Jin S \& Lin Y-F $2014 b$ Expression of soluble vascular endothelial growth factor receptor-1 and placental growth factor in FGR and intervention effect of tetramethylpyrazine. Asian Pacific Journal of Tropical Medicine 7 663-667. (doi:10.1016/S19957645(14)60112-7)

Liang Y, Lin Q, Luo F, Wu W, Yang T \& Wan S 2014 Requirement of miR144 in CsA induced proliferation and invasion of human trophoblast cells by targeting titin. Journal of Cellular Biochemistry 115 690-696. (doi:10.1002/jcb.24710)

Lim R, Barker G, Liong S, Nguyen-Ngo C, Tong S, Kaitu'u-Lino T \& Lappas M 2016 ATF3 is a negative regulator of inflammation in human fetal membranes. Placenta 47 63-72. (doi:10.1016/j. placenta.2016.09.006)

Lima PD, Zhang J, Dunk C, Lye SJ \& Croy BA 2014 Leukocyte drivendecidual angiogenesis in early pregnancy. Cellular and Molecular Immunology 11 522-537. (doi:10.1038/cmi.2014.63)

Lin D, Smith MA, Champagne C, Elter J, Beck J \& Offenbacher S 2003a Porphyromonas gingivalis infection during pregnancy increases maternal tumor necrosis factor alpha, suppresses maternal interleukin-10, and enhances fetal growth restriction and resorption in mice. Infection and Immunity 71 5156-5162. (doi:10.1128/IAI.71.9.5156-5162.2003)

Lin D, Smith MA, Elter J, Champagne C, Downey CL, Beck J \& Offenbacher S 2003b Porphyromonas gingivalis infection in pregnant mice is associated with placental dissemination, an increase in the placental Th1/Th2 cytokine ratio, and fetal growth restriction. Infection and Immunity 71 5163-5168. (doi:10.1128/IAI.71.9.5163-5168.2003)

Lo TK, Chan KY, Chan SS, Kan AS, Hui AP \& Tang MH 2015 Pregnancyassociated plasma protein A for prediction of fetal growth restriction. International Journal of Gynecology and Obstetrics $\mathbf{1 3 0} 200$. (doi:10.1016/j.ijgo.2015.02.016)

Lo TK, Yuen-Kwong Chan K, Sik-Yau Kan A, Pui-Wah Hui A, Wan-Man Shek N \& Hoi-Yin Tang M 2016 Pregnancy-associated plasma protein A (PAPP-A) to predict adverse fetal outcomes in Chinese: What is the optimal cutoff value? Journal of Obstetrics and Gynaecology 36 902-903. (doi:10.3109/01443615.2016.1174201)

Longo S, Borghesi A, Tzialla C \& Stronati M 2014 IUGR and infections. Early Human Development 90 S42-S44. (doi:10.1016/S03783782(14)70014-3)

Luo L, Ye G, Nadeem L, Fu G, Yang BB, Honarparvar E, Dunk C, Lye S \& Peng C 2012 MicroRNA-378a-5p promotes trophoblast cell survival, 
migration and invasion by targeting Nodal. Journal of Cell Science 125 3124-3132. (doi:10.1242/jcs.096412)

Maulik D, De A, Ragolia L, Evans J, Grigoryev D, Lankachandra K, Mundy D, Muscat J, Gerkovich MM \& Ye SQ 2016 Down-regulation of placental neuropilin-1 in fetal growth restriction. American Journal of Obstetrics and Gynecology 214279 e271-e279. (doi:10.1016/j.ajog.2015.09.068)

Mifsud W \& Sebire NJ 2014 Placental pathology in early-onset and lateonset fetal growth restriction. Fetal Diagnosis and Therapy 36 117-128. (doi:10.1159/000359969)

Miguel Constância MH, Hughes J, Dean W, Ferguson-Smith A, Fundele R, Stewart F, Kelsey G, Fowden A, Sibley C \& Reik W 2002 Placentalspecific IGF-II is a major modulator of placental and fetal growth. Nature 417 945-948. (doi:10.1038/nature00819)

Mikaelsson MA, Constancia M, Dent CL, Wilkinson LS \& Humby T 2013 Placental programming of anxiety in adulthood revealed by Igf2-null models. Nature Communications 42311.

Miller SL, Huppi PS \& Mallard C 2016 The consequences of fetal growth restriction on brain structure and neurodevelopmental outcome. Journal of Physiology 594 807-823. (doi:10.1113/JP271402)

Moffett A \& Colucci F 2015 Co-evolution of NK receptors and HLA ligands in humans is driven by reproduction. Immunological Reviews 267 283-297. (doi:10.1111/imr.12323)

Moffett A, Hiby SE \& Sharkey AM 2015 The role of the maternal immune system in the regulation of human birthweight. Philosophical Transactions of the Royal Society B: Biological Sciences 37020140071. (doi:10.1098/rstb.2014.0071)

Monier I, Blondel B, Ego A, Kaminiski M, Goffinet F \& Zeitlin J 2015 Poor effectiveness of antenatal detection of fetal growth restriction and consequences for obstetric management and neonatal outcomes: a French national study. BJOG 122 518-527. (doi:10.1111/14710528.13148)

Mouillet JF, Ouyang Y, Coyne CB \& Sadovsky Y 2015 MicroRNAs in placental health and disease. American Journal of Obstetrics and Gynecology 213 S163-S172. (doi:10.1016/j.ajog.2015.05.057)

Murthi P, Brouillet S, Pratt A, Borg A, Kalionis B, Goffin F, Tsatsaris V, Munaut C, Feige J, Benharouga M et al. 2015 An EG-VEGF-dependent decrease in homeobox gene NKX3.1 contributes to cytotrophoblast dysfunction: a possible mechanism in human fetal growth restriction. Molecular Medicine 21 645-656.

Murthi P, Faisal FA, Rajaraman G, Stevenson J, Ignjatovic V, Monagle PT, Brennecke SP \& Said JM 2010 Placental biglycan expression is decreased in human idiopathic fetal growth restriction. Placenta 31 712-717. (doi:10.1016/j.placenta.2010.05.009)

Nardozza LM, Araujo Junior E, Barbosa MM, Caetano AC, Lee DJ \& Moron AF 2012 Fetal growth restriction: current knowledge to the general Obs/ Gyn. Archives of Gynecology and Obstetrics 286 1-13. (doi:10.1007/ s00404-012-2330-6)

Ornoy A 2011 Prenatal origin of obesity and their complications: Gestational diabetes, maternal overweight and the paradoxical effects of fetal growth restriction and macrosomia. Reproductive Toxicology 32 205-212. (doi:10.1016/j.reprotox.2011.05.002)

Peng W, Chen Y, Luo X, Shan N, Lan X, Olson D, Zhang H, Ding YB \& Qi HB 2016 DNA methylation-associated repression of MEST/PEG1 expression contributes to the invasion of extravillous trophoblast cells. Placenta 46 92-101. (doi:10.1016/j.placenta.2016.08.093)

Piyasena C, Reynolds RM, Khulan B, Seckl JR, Menon G \& Drake A 2015 Placental 5-methylcytosine and 5-hydroxymethylcytosine patterns associate with size at birth. Epigenetics 10 692-697. (doi:10.1080/1559 2294.2015.1062963)

Poudel R, Stanley JL, Rueda-Clausen CF, Andersson IJ, Sibley CP, Davidge ST \& Baker PN 2013 Effects of resveratrol in pregnancy using murine models with reduced blood supply to the uterus. PLOS ONE 8 e64401. (doi:10.1371/journal.pone.0064401)

Qiu Q, Bell M, Lu X, Yan X, Rodger M, Walker M, Wen SW, Bainbridge S, Wang H \& Gruslin A 2012 Significance of IGFBP-4 in the development of fetal growth restriction. Journal of Clinical Endocrinology and Metabolism 97 E1429-E1439. (doi:10.1210/jc.2011-2511)

Raghupathy R, Al-Azemi M \& Azizieh F 2012 Intrauterine growth restriction: cytokine profiles of trophoblast antigen-stimulated materna lymphocytes. Clinical and Developmental Immunology 2012734865.

Robson A, Harris LK, Innes BA, Lash GE, Aljunaidy MM, Aplin JD, Baker PN, Robson SC \& Bulmer JN 2012 Uterine natural killer cells initiate spiral artery remodeling in human pregnancy. FASEB Journal 26 4876-4885. (doi:10.1096/fj.12-210310)

Rolfo A, Garcia J, Todros T, Post M \& Caniggia I 2012 The double life of MULE in preeclamptic and IUGR placentae. Cell Death and Disease 3 e305. (doi:10.1038/cddis.2012.44)

Seravalli V \& Baschat AA 2015 A uniform management approach to optimize outcome in fetal growth restriction. Obstetrics and Gynecology Clinics of North America 42 275-288. (doi:10.1016/j.ogc.2015.01.005)

Stanley JL, Andersson IJ, Hirt CJ, Moore L, Dilworth MR, Chade AR, Sibley CP, Davidge ST \& Baker PN 2012 Effect of the anti-oxidant tempol on fetal growth in a mouse model of fetal growth restriction. Biology of Reproduction 87 25, 21-28. (doi:10.1093/biolreprod/87.s1.21)

Swanson AM \& David AL 2015 Animal models of fetal growth restriction: considerations for translational medicine. Placenta 36 623-630. (doi:10.1016/j.placenta.2015.03.003)

Szentpeteri I, Rab A, Kornya L, Kovacs P \& Joo JG 2013 Gene expression patterns of vascular endothelial growth factor (VEGF-A) in human placenta from pregnancies with intrauterine growth restriction. Journal of Maternal-Fetal and Neonatal Medicine 26 984-989. (doi:10.3109/14 767058.2013.766702)

Tamaru S, Mizuno Y, Tochigi H, Kajihara T, Okazaki Y, Okagaki R, Kamei Y, Ishihara O \& Itakura A 2015 MicroRNA-135b suppresses extravillous trophoblast-derived HTR-8/SVneo cell invasion by directly down regulating CXCL12 under low oxygen conditions. Biochemical and Biophysical Research Communications 461 421-426. (doi:10.1016/j. bbrc.2015.04.055)

Tang Q, Wu W, Xu X, Huang L, Gao Q, Chen H, Sun H, Xia Y, Sha J, Wang X, Chen D \& Xu Q 2013 miR-141 contributes to fetal growth restriction by regulating PLAG1 expression. PLOS ONE 8 e58737. (doi:10.1371/ journal.pone.0058737)

Thompson LP, Pence L, Pinkas G, Song H \& Telugu BP 2016 Placental hypoxia during early pregnancy causes maternal hypertension and placental insufficiency in the hypoxic guinea pig model. Biology of Reproduction 95 128. (doi:10.1095/biolreprod.116.142273)

Tilburgs T, Crespo AC, van der Zwan A, Rybalov B, Raj T, Stranger B, Gardner L, Moffett A \& Strominger JL 2015 Human HLA-G+ extravillous trophoblasts: immune-activating cells that interact with decidual leukocytes. PNAS 112 7219-7224. (doi:10.1073/ pnas.1507977112)

Tintu A, Rouwet E, Verlohren S, Brinkmann J, Ahmad S, Crispi F, van Bilsen M, Carmeliet P, Staff AC, Tjwa M et al. 2009 Hypoxia induces dilated cardiomyopathy in the chick embryo: mechanism, intervention, and long-term consequences. PLOS ONE 4 e5155. (doi:10.1371/journal. pone.0005155)

Tunster SJ, Creeth HD \& John RM 2016 The imprinted Phlda2 gene modulates a major endocrine compartment of the placenta to regulate placental demands for maternal resources. Developmental Biology 409 251-260. (doi:10.1016/j.ydbio.2015.10.015)

Tunster SJ, Van de Pette M \& John RM 2011 Fetal overgrowth in the Cdkn1c mouse model of Beckwith-Wiedemann syndrome. Disease Models and Mechanisms 4 814-821. (doi:10.1242/dmm.007328)

Vesce F, Cagnazzo E, Giugliano E, Mossuto E \& Marci R 2014 The behaviour of the peripheral natural killer cells in the foetal growth restriction. European Review for Medical and Pharmacological Sciences $182248-2252$.

Wallace AE, Goulwara SS, Whitley GS \& Cartwright JE 2014 Oxygen modulates human decidual natural killer cell surface receptor expression and interactions with trophoblasts. Biology of Reproduction 91134.

Wallace AE, Host AJ, Whitley GS \& Cartwright JE 2013 Decidual natural killer cell interactions with trophoblasts are impaired in pregnancies at increased risk of preeclampsia. American Journal of Pathology 183 1853-1861. (doi:10.1016/j.ajpath.2013.08.023)

Wallace AE, Whitley GS, Thilaganathan B \& Cartwright JE 2015 Decidual natural killer cell receptor expression is altered in pregnancies with impaired vascular remodeling and a higher risk of pre-eclampsia. Journal of Leukocyte Biology 97 79-86. (doi:10.1189/jlb.2A0614-282R)

Weaver JR \& Bartolomei MS 2014 Chromatin regulators of genomic imprinting. Biochimica et Biophysica Acta 1839 169-177. (doi:10.1016/j. bbagrm.2013.12.002)

Whitehead CL, McNamara H, Walker SP, Alexiadis M, Fuller PJ, Vickers DK, Hannan NJ, Hastie R, Tuohey L, Kaitu'u-Lino TJ \& Tong S 2016 Identifying late-onset fetal growth restriction by measuring 
circulating placental RNA in the maternal blood at 28 weeks' gestation. American Journal of Obstetrics and Gynecology 214 521.e1-521.e8. (doi:10.1016/j.ajog.2016.01.191)

Whitehead CL, Teh WT, Walker SP, Leung C, Larmour L \& Tong S 2013 Circulating MicroRNAs in maternal blood as potential biomarkers for fetal hypoxia in-utero. PLOS ONE 8 e78487. (doi:10.1371/journal. pone.0078487)

Williams PJ, Bulmer JN, Searle RF, Innes BA \& Robson SC 2009 Altered decidual leucocyte populations in the placental bed in pre-eclampsia and foetal growth restriction: a comparison with late normal pregnancy. Reproduction 138 177-184. (doi:10.1530/REP-09-0007)

Wu WL, Hsiao EY, Yan Z, Mazmanian SK \& Patterson PH 2017 The placental interleukin-6 signaling controls fetal brain development and behavior. Brain, Behavior, and Immunity 62 11-23. (doi:10.1016/j. bbi.2016.11.007)

Xie L, Mouillet J-F, Chu T, Parks WT, Sadovsky E, Knöfler M \& Sadovsky Y 2014 C19MC MicroRNAs regulate the migration of human trophoblasts. Endocrinology 155 4975-4985. (doi:10.1210/en.2014-1501)

Xiong S, Sharkey AM, Kennedy PR, Gardner L, Farrell LE, Chazara O, Bauer J, Hiby SE, Colucci F \& Moffett A 2013 Maternal uterine NK cellactivating receptor KIR2DS1 enhances placentation. Journal of Clinical Investigation 123 4264-4272. (doi:10.1172/JCl68991)

Yang M, Chen Y, Chen L, Wang K, Pan T, Liu X \& Xu W 2016 miR-15bAGO2 play a critical role in HTR8/SVneo invasion and in a model of angiogenesis defects related to inflammation. Placenta 41 62-73. (doi:10.1016/j.placenta.2016.03.007)
Yu Y, Wang L, Liu T \& Guan H 2015 MicroRNA-204 suppresses trophoblast-like cell invasion by targeting matrix metalloproteinase-9. Biochemical and Biophysical Research Communications 463 285-291. (doi:10.1016/j.bbrc.2015.05.052)

Zhang J, Dunk CE \& Lye SJ 2013 Sphingosine signalling regulates decidual NK cell angiogenic phenotype and trophoblast migration. Human Reproduction 28 3026-3037. (doi:10.1093/humrep/det339)

Zhu J, Zhong M, Pang Z \& Yu Y 2014 Dysregulated expression of matrix metalloproteinases and their inhibitors may participate in the pathogenesis of pre-eclampsia and fetal growth restriction. Early Human Development 90 657-664. (doi:10.1016/j.earlhumdev.2014. 08.007)

Zohdi V, Lim K, Pearson JT \& Black MJ 2015 Developmental programming of cardiovascular disease following intrauterine growth restriction: findings utilising a rat model of maternal protein restriction. Nutrients 7 119-152. (doi:10.3390/nu7010119)

Received 19 June 2016

First decision 24 August 2016

Revised manuscript received 21 February 2017

Accepted 14 March 2017 